\title{
A Historical Analysis of Barrow's Theorem and Its Educational Implication
}

Barrow 정리의 수학사적 분석과 그에 따른 교육적 시사점에 대한 연구

\author{
PARK SunYong 박선용
}

\begin{abstract}
This study is to analyse the characteristics of Barrow's theorem on the historical standpoint of hermeneutics and to discuss the teaching-learning sequence for guiding students to reinvent the calculus according to historico-genetic principle. By the historical analysis on the Barrow's theorem, we show the geometric feature of the theorem, conjecture the Barrow's intention in dealing with it, and consider the epistemological obstacles undergone by Barrow. On a basis of this result, we suggest a purposeful and meaning-oriented teaching-learning way for students to realize the sameness of the 'integration' and 'anti-differentiation', and point out the shortcomings and supplement point in current School Mathematic Calculus.
\end{abstract}

Keywords: Barrow's theorem, epistemological obstacles, historico-genetic principle; Barrow 정리, 인식론적 장애, 역사발생적 원리.

MSC: 01A45 ZDM: A34

\section{1 서론}

Child[12]가 Issac Barrow(1630-1677)의 수학적 업적에 대해 연구한 이후, 20세기 수 학사학계에서는 Barrow 가 Newton의 미적분학 창안에 정확히 어떤 기여를 했는지에 대해 판단하는 연구가 이루어져 왔다. Child[13]는 "Newton은 개인적 의사교환을 통해 Barrow로부터 주요한 아이디어를 얻었다; 그리고 Leibniz 또한 1673년에 출간된 Barrow의 책으로부터 자신의 독창적 아이디어의 확인이라는 면에서 그리고 이후 발전방향 에의 시사라는 면에서 어느 정도 도움을 받았다(p.viii).”고 주장하면서, Barrow가 미 적분학 발달에 끼친 공헌이 매우 크다는 입장을 나타낸다. 이후, 20세기의 Barrow에 대한 수학사 연구는 균형점을 찾으려는 시도라 할 수 있는데, Coolidge[15]가 Child의 Barrow에 대한 수학사적 평가가 찬양에 가까울 정도로 지나친 측면이 있다는 입장을

이 논문은 2011년도 정부재원(교육과학기술부 신진연구자지원사업비)으로 한국학술진흥재단의 지원을 받아 연구되었음 (NRF-332-2011-1-B00472).

Receiveded on Nov. 14, 2012, revised on Jau. 16, 2013, accepted on Jau. 23, 2013. 
나타낸 것은 그 전형을 보여준다.

수학사를 분석하고 저술하는 역사-기술적(historiographic) 방법의 변화에도 불구하 고, 수학의 발달을 목적론적(teleological) 방식으로 보려는 경향은 항상 있어왔다. 오늘 날의 기호만 도입되지 않았을 뿐 과거의 수학자들이 현대적 개념을 사용했다는 주장을 제기해왔던 것인데, 미적분학사의 경우도 예외는 아니었다. 물론, 수학사를 분석함에 있 어 이러한 단점을 보완하기 위해, 오늘날이 아닌 당시의 수학적 관점이 무엇인지를 진 지하게 파악하려는 시도, 즉 어떤 시대의 수학의 장점과 한계가 무엇인지를 알기 위해 당시 수학자의 의도가 무엇인지를 알아내려는 해석학적 연구(hermeneutic study) 가 요 구된다.

그런데 이러한 해석학적 수학사 연구는 수학의 발달을 학생들의 심리발달과 정교하게 연결시킬 뿐 아니라 학교수학의 교수-학습 활동을 설계하는 데에 도움이 될 수 있다. 수 학의 발달을 진전과 한계의 관점으로 조명하는 과정 속에서 해당 시대에 겪었던 '인식 론적 장애 ${ }^{1)}$ (epistemological obstacles)' 를 규명할 수 있는데, 이러한 '인식론적 장애' 의 틀은 학생들의 수학을 학습하는 과정과 수학의 역사적 발달을 연결시키고 수학사를 기반으 로 한 교실활동을 계획하는 데에 그 방법론적 기초를 제공하기 때문이다[26].

사실, 이 연구에서 인식론적 장애의 틀에 의해 수학사와 학생의 발달 및 수학 교수-학습 상황의 구성을 연결시키는 작업은 수학사 자체에 대해서는 해석학적 분석을 시도하지만 수학-교수 학습에 있어서는 이러한 분석을 바탕으로 학생의 현실과 접목시켜 일종의 재구 성된 역사를 교수-학습에 투여하는 과정이라 할 수 있다 $[3,6]$.

Klein과 Poincare 등이 주창한 고전적인 역사발생적 교수-학습 원리의 경우, 수학의 발 달을 누적적이고 연속적인 과정으로 보면서 개체발생이 계통발생을 재현하다는 원리를 심 리발달에 적용해 수학의 발달과 교수-학습 과정을 내용적 측면에서 서로 연결시키려고 했다 면, 이 연구에서는 그러한 내용적 유사성이 아니라 발달 메커니즘의 유사성, 곧 <대상 $\rightarrow$ 대 상 사이의 관계 $\rightarrow$ 관계의 구조 $\rightarrow$ 구조의 대상화 $\rightarrow \cdots>$ 의 순환적 메커니즘이 계통발생과 개 체발생을 일관되게 설명할 수 있는 발달 메커니즘이라는 가정을 하고서, 오히려 그러한 발 달의 불연속적 과정에 주목한다. 또한, 수학의 발달과 심리 발달을 연결함에 있어서 내용의 재현이 아니라, 수학의 불연속적 성장 과정에 대한 분석을 바탕으로 하여, 학습자가 그들의 현실에 맞게 일종의 학습 수준의 상승을 경험할 수 있는 상황을 구성하는 데에 초점을 둔다.

이 연구에서는 수학사에 대한 해석학적 분석과 현대적인 역사발생적 교수-학습 원리의 결합을 시도한다고 할 수 있는데, 그 이유는 이 연구의 대상이 학교수학 미적분학에 대한

1) 이 연구에서는 '인식론적 장애는 학습자의 인지구조의 일부인 지식으로, 어떤 특정한 맥락에서는 성공적이고 유용했던 지식이었지만 새로운 문제 상황이나 더 넓은 문맥에서는 부적합해진 지식' 이라는 Brousseau[11] 의 인식론적 장애에 대한 정의를 수용한다. Sierpinska[27]가 지적했듯, 인식론적 장애를 어떤 특정한 조작적 정의로 규정하는 것은 힘든 일이지만, 이 연구에서 Brousseau의 인식론적 장애에 대한 정의를 받아들이는 것은 그의 정의가 수학사와 교육의 관련성에 초점을 두고 있기 때문이다. 
교수-학습인 것과 관련이 있다. 다시 말해, 학생들이 어느 정도 미적분학에 대한 지식을 가지고 있을 때에는 미적분학사 자료를 분석하고 17 세기 사회문화와 수학의 상황을 살펴 보는 해석학적 방법을 수학 교수-학습에도 접목시키는 접근이 가능하고, 문화적 소양의 습 득과 수학적 이해의 심화와 같은 교육적 효과를 기대할 수 있지만, 미적분학을 처음 접하는 학생들의 경우에는 Barrow 의 원전을 강독하는 수준의 활동을 수행하게 하는 것이 사실상 어렵고 그 교육적 효과 역시 크다고 기대할 수 없기 때문이다[21, 22].

한편, Barrow 에 관한 수학사 연구를 수학교육에 접목시키려는 시도는 Flashman[19] 에 의해 이루어진 바 있다. 그의 연구에서는 미국의 대학생들에게 함수에 기초한 현대적인 미적분학과 Barrow 의 정리를 비교하고 그 차이를 인식하게 하여, 그들이 미적분학에 대해 개념적으로 깊이 이해하고 수학을 인간의 문화적 활동으로 바라볼 수 있도록 하자는 제안 을 하였다. 하지만, 앞서 밝혔듯, 이러한 접근방식은 미적분학을 처음 도입하는 고등학교 상황에서는 적합하다고 할 수 없다.

이런 점에서, 이 연구는 인식론적 장애의 틀을 가지고 Flashman의 Barrow에 대한 수 학사적 그리고 교육적 연구를 고등학교 수준에서 재조직하는 작업에 해당한다고 하겠다. 이를 위해, 다음 장에서는 Flashman의 Barrow 정리와 그 증명에 대한 수학사적 분석에 대해서부터 논의하기 시작한다.

\section{Barrow 정리에 대한 수학사적 분석}

Barrow 가 1670 년에 펴낸 13 개의 <기하학 강의록> 중 10 번째에 수록되어 있는, 흔히 미적 분학의 기본정리의 전신으로 알려진, Barrow 정리는 다음과 같다2).

Barrow 정리 곡선 $A$ 는 곡선 $Y, x$-축, 선분 $X Q$ 에 의해 둘러싸인 평면의 넓이와 같은 길 이의 선분 $X P$ 를 높이로 갖는다. 이때, $T X \times X Q$ 와 $X P$ 의 값이 같도록 $x$ 축 위의 점 $T$ 를 잡으면, 직선 $T P$ 는 곡선 $A$ 의 점 $P$ 에서의 접선이 된다.

Barrow 정리에 대한 증명 편의상 $X$ 가 증가할 때, $X Q$ 의 길이는 증가하고 곡선 $A$ 에서 점 $R$ 은 점 $P$ 의 앞에 위치한다고 가정하자. $X$ 축과 평행하면서 $R$ 을 지나는 직선을 그려라. 이때, 이 직선은 직선 $T P$ 와 점 $S$ 에서 만나고 직선 $X P$ 와 점 $U$ 에서 만나게 된다. 이제, $R \neq S$ 임 을 보여주기만 하면 된다. 삼각형 $T P X$ 는 삼각형 $S P U$ 와 닮음이므로, $Q X=\frac{P X}{T X}=\frac{P U}{S U}$ 이 성립한다. 양변에 $S U$ 를 곱하면 $Q X \times S U=P U$ 이 성립한다. $P X Q$ 에 평행하며 $X$ 축, 곡선 $Y$, 곡선 $A$ 와 각각 $V, W, R$ 에서 만나는 직선을 그리면, $R V$ 의 길이는 곡선 $Y, X$ 축, 선분 $W V$ 에 의해 둘러싸인 넓이와 같다. $R V=U X, P X=P U+U X$ 에 의하여 $P U$

2) Barrow 정리에 대한 현대 영문은 $[12,13,14,24,29]$ 등에도 소개되어 있다. 그런데 이 연구가 Flashman [19]의 연구로부터 출발했고 그의 제시방식이 몇몇 기호를 제외하곤 Barrow의 원문에 충실하면서 쉽게 서술되어 있기 때문에, 이 연구에서 도입한 Barrow 정리와 그에 대한 증명은 Flashman이 도입한 기호에 기초하기로 한다. 


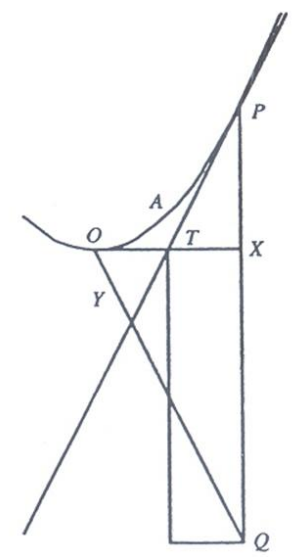

그림 1

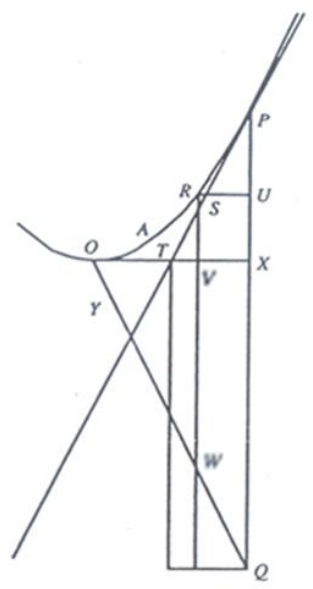

그림2

는 선분 $V W, V X, X Q$ 와 $Q$ 와 $W$ 사이의 곡선으로 둘러싸인 넓이와 같은 길이를 갖는다. 그러나 이 영역은 $V X$ 와 $X Q$ 에 의해 이루어진 직사각형 안에 있으므로 $P U$ 는 $Q X$ 와 $V X$ 의 곱보다 작다. 따라서 $Q X \times S X<Q X \times V X$ 이고 $S U<V X$ 이다. 그러나 $V X=R U$ 이므로 $S U<R U$ 이고, $R \neq S$ 라고 할 수 있다. 끝.

위의 증명 과정에서 ' $R \neq S$ 임을 보여주기만 하면 된다.' 는 것은, 점 $P$ 를 제외한 곡선 $A$ 위에 있는 어떠한 점도 직선 $T P$ 와 만나지 않는다는 것을 입증하면 된다는 의미이다. Barrow는 어떤 곡선과 스치듯 한 점에서 만나는 직선을 그 곡선에 대한 접선으로 받아들 이고, 선 $A$ 에서 점 $R$ 은 점 $P$ 의 앞에 위치한다고 가정하고서, 점 $P$ 를 제외한 곡선 $A$ 위의 임의의 점 $R$ 이 직선 $T P$ 와 만나지 않는다는 것을 보임으로써, 직선 $T P$ 가 점 $P$ 에서 곡선 $A$ 에 접하는 접선임을 보이고자 했던 것이다.

그렇다면, 이러한 Barrow 정리와 그것에 대한 증명 과정은 무엇을 드러내려는 것일까? 우선, Barrow 정리는 곡선 $A$ 위의 점에서 접선을 긋는 방법을 알려준다고 할 수 있다. 그리 고 그 작도법은 선분 $X P$ 와 선분 $X Q$ 가 주어져 있을 때, 선분 $X Q$ 와 선분 $T X$ 를 두 변으로 직사각형의 넓이가 선분 $X P$ 의 길이와 같도록 점 $T$ 를 작도하는 것이다. 하지만 Barrow 정리의 진정한 의미는 곡선 $Y, x$-축, 선분 $X Q$ 에 의해 둘러싸인 평면의 넓이를 나타내는 곡선 $A$ 의 접선을 왜 찾으려고 하는지에 의해 결정된다고 할 수 있다. 우리는 그것에 대한 단서를 시간과 운동의 문제를 다루는 Barrow 의 <기하학 강의록> 전체적 구성을 통해 살 펴볼 수 있다.

Barrow는 <기하학 강의록> 전반부에서, 시간은 운동에 의해 잴 수 있는 양 또는 일정하 게 흐르는 연속적 크기로 간주하면서, Oresme와 Galileo의 방식으로 시간과 운동의 크기 를 다루고, 점과 직선의 움직임에 의해 각각 곡선과 넓이의 생성을 설명한다. 그리고 거리의 크기를 나타내는 곡선의 기울기는 순간속도를 나타내며, 어떤 곡선 아래의 넓이를 구했을 
때 그 크기가 거리를 나타내도록 작도한다면 그 곡선은 속도의 크기를 나타내는 것)이라 말하였다[7]. 그리고 <기하학 강의록>10에서 Barrow 정리를 다루기에 앞서, "나는 한두 가지 정리를 더 보태려고 한다. 그것은 매우 일반적인 것처럼 보이는데, 결코 사소하게 넘 길 사항은 아니다.”고 주장하였다([29], p. 255). 이러한 <기하학 강의록> 의 전체적 체계는 Barrow 정리가 변화량과 변화율 사이의 일반적 관계를 드러내는 명제임을 알려준다고 하 겠다.

이런 사항에 초점을 맞추어, Barrow 가 곡선 $Y, x$-축, 선분 $X Q$ 에 의해 둘러싸인 평면의 넓이를 나타내는 곡선 $A$ 의 접선을 찾는 작도법을 제시한 이유를 다음 두 가지 차원에서 해석할 수 있다.

첫 번째 해석은, Barrow는 어떤 변화량에 대한 변화율의 크기를 나타내는 곡선 아래의 넓이가 원래의 변화량의 크기가 된다는 것을 입증하려고 한 것이 아니라, 그러한 사실 자체 만을 설명하려고 한 것이라는 해석이 가능하다. 만약 Barrow 가 곡선 $A$ 가 곡선 $Y$ 에 대한 변화량 곡선이 된다는 것 ${ }^{4)}$ 을 직접 증명해 보이려 했다면, 다음과 같은 명제를 증명해야 했을 것이다.

곡선 $A$ 는 곡선 $Y, x$-축, 선분 $X Q$ 에 의해 둘러싸인 평면의 넓이와 같은 길이의 선분 $X P$ 를 높이로 갖는다. 이때, 직선 $T P$ 가 곡선 $A$ 의 점 $P$ 에서의 접선이 되도록 $x$ 축 위의 점 $T$ 를 잡는다면, $T X \times X Q$ 와 $X P$ 가 같게 된다.

이러한 해석의 핵심은 Barrow가 "직선 $T P$ 가 곡선 $A$ 의 점 $P$ 에서의 접선이 되도록 $x$ 축 위의 점 $T$ 를 잡는다면, $T X \times X Q$ 와 $X P$ 가 같게 된다." 는 명제를 증명한 것이 아니라 " $T X \times X Q$ 와 $X P$ 의 값이 같도록 $x$ 축 위의 점 $T$ 를 잡으면, 직선 $T P$ 는 곡선 $A$ 의 점 $P$ 에 서의 접선이 된다.”는 작도법과 그에 대한 증명만을 제시했다는 점이다. 다시 말해, Barrow 정리는 변화율을 나타내는 곡선인 $Y, x$-축, 선분 $X Q$ 에 의해 둘러싸인 평면의 넓이를 나 타내는 곡선 $A$ 의 성격이 변화량을 나타낸다는 사실만을 드러내려 한 것이라 볼 수 있는 것이다. 이 경우, Barrow 정리에 대한 평가는 변화율 곡선 아래의 넓이가 원래의 변화량 곡선이 된다는 것을 기하학적으로 설명하려고 했다는 것이 적합할 것이다.

두 번째 해석은, Barrow 가 이 정리를 통해 어떤 변화량에 대한 변화율의 크기를 나타내

3) Barrow는 연속적 크기와 관련해, "크기들이 한 순간 또는 점의 연속적 흐름으로 이루어지거나, 순간 또는 점들의 집합으로 생각될 수 있다.”는 운동학적 견해와 원자론적 견해가 혼합된 의견을 가지고 있다. 그리고 그는 이러한 가정아래 시간-속도 곡선 아래의 넓이가 거리를 나타낸다는 것을 "시간을 나타내는 직선의 모든 점을 지나는 평행선들이 그려지면, 평행한 직선들의 집합이 되는 평면은 각각의 직선이 그것이 지나는 점에 대응되는 속도의 정도를 나타낼 때, 속도의 정도의 집합에 정확히 대응되어서, 지나는 공간을 또한 나타내 도록 가장 편리하게 조절될 수 있다.”고 밝히고 있다[10, p. 206 재인용].

4) 오늘날의 용어로, 변화량 곡선은 역도함수(원시함수)의 그래프에 해당한다. 한편, Barrow 정리에서는 변 화율 곡선과 변화량 곡선의 처음 높이를 모두 0 으로 간주함으로써, 어떤 변화율 곡선에 대한 변화량 곡선이 유일하게 정해지도록 하였다. 이것은, 기울기 (변화율)가 매순간 같은 두 곡선이 처음 값만 일치하면 본질상 같은 곡선이 될 것이라는 직관을 활용한 모습을 보여준다. 
는 곡선 아래의 넓이가 다시 그 변화량의 크기가 된다는 것을 직접 입증하려 했다고 보는 것이다.

이러한 해석에 대한 첫 번째 논거는 접선의 존재성과 유일성에 기초한다. 즉, 암묵적으로 가정하고 있는 접선의 유일한 존재성에 기초한다면, 그의 증명은 "직선 $T P$ 가 곡선 $A$ 의 점 $P$ 에서의 접선이 되도록 $x$ 축 위의 점 $T$ 를 잡는다면, $T X \times X Q$ 와 $X P$ 가 같게 된다." 을 증명한 것이나 다름없게 된다. 왜냐하면 곡선 $Y$ 와 곡선 $A$ 가 이미 주어진 상태에서는 ' $T X \times X Q=X P$ ' 을 만족하는 $x$ 축 위의 점 $T$ 는 항상 찾을 수 있기에, 곡선 $A$ 에 대한 접선은 항상 존재한다. 그리고 그러한 접선은 유일하기에, ' $T X \times X Q=X P$ ' 조건은 $x$ 축 위의 점 $T$ 에 대해 '직선 $T P$ 가 곡선 $A$ 의 점 $P$ 에서의 접선이 된다.' 는 조건에 대한 충분조 건이 될 뿐만 아니라, 접선의 유일한 존재성에 의해, 필요조건도 되기 때문이다.

두 번째 해석에 대한 두 번째 논거로, 첫 번째 논거에 더해 Barrow가 이미 일명 Fermat 의 미분삼각형 기법과 유사한 접선법을 구사했다는 역사적 사실을 고려해, 이러한 사항을 Barrow 정리의 증명에 접목시키면 원하는 결과를 비교적 쉽게 얻을 수 있다는 점을 들 수 있다. 분명히, Barrow는 일종의 미분삼각형을 다룰 수 있었다[8, 23]. 그렇기에, Barrow 정리에 제시된 증명방식 안에 담긴 증명의 아이디어에 기초해, 만약 그가 미분삼각형 접 선법을 Barrow 정리의 증명과정에 적용했다면 “직선 $T P$ 가 곡선 $A$ 의 점 $P$ 에서의 접선이 되도록 $x$ 축 위의 점 $T$ 를 잡는다면, $T X \times X Q$ 와 $X P$ 가 같게 된다." 를 아주 쉽게 보일 수 있을 것으로 추측된다. 개략적으로, 그 방식은 다음과 같을 것이다(그림2 참조).

만약 점 $R$ 이 점 $P$ 에 가까이 있으면 삼각형 $R P U$ 가 매우 작아지게 되어, 삼각 형 $R P U$ 와 삼각형 $S P U$ 가 거의 같아지게 되고, 이 때 삼각형 $R P U$ 는 삼각형 $T P X$ 와 닮게 되고 $\frac{\text { 사각형 } V W Q X}{V X}$ 은 높이가 $Q X$ 인 가느다란 직사각형 또는 직선처럼 되므로, $\frac{P X}{T X}=\frac{P U}{R U}=\frac{\text { 사각형 } V W Q X}{V X}=Q X$ 임을 알 수 있다.

이러한 추측은, Barrow 정리의 증명 안에 접선법에 의해 "직선 $T P$ 가 곡선 $A$ 의 점 $P$ 에서의 접선이 되도록 $x$ 축 위의 점 $T$ 를 잡는다면, $T X \times X Q$ 와 $X P$ 가 같게 된다."를 입증해줄 수 있는 아이디어가 이미 들어가 있다는 것을 보여준다. 하지만 Barrow 가 종합적 방법이 아닌 해석적 방법으로도 $\frac{P X}{T X}=Q X$ 를 입증할 수 있었다는 가정을 기초로 한 개연적 추 측과 그에 따른 해석은 자칫 Barrow를 무한소 미적분학의 첫 번째 발명자로 단정해버리는 결과를 낳는다.

Barrow 정리에 대한 증명자체는 $R \neq S$ 이라는 것, 즉 삼각형 $S P U$ 와 삼각형 $R P U$ 가 다르다는 것을 기하학적으로 보여주는 과정인데, 이 증명과정은 '삼각형 $R P U$ 와 삼각형 $S P U$ 가 거의 같다.' 는 전제와는 근본적으로 상충한다. 비록 Barrow 가 호 $R P$ 가 무한히 작을 때 그것을 접선의 아주 작은 부분으로 인정하는 논의를 한 적이 있다 하더라도, 두 번째 해석에 대한 두 번째 논거는 일관성 측면에서 설득력이 약하다고 하겠다. 사실, Barrow는 
극한을 산술적으로 다룬 적이 없으며 접선법을 연산적 형태로 발전시킨 적이 없기 때문에, 이러한 두 번째 논거는 사실상 타당하다고 할 수 없다[9].

한편, Barrow 정리를 산술적으로 또는 오늘날의 해석적 표기법으로 해석하는 시도는, 그에 대해 심지어 도함수와 정적분 개념을 가지고 있었다는 잘못된 판단을 내릴 위험까지 낳게 된다. 이와 관련해, Flashman[19]은, 직선의 현대적인 기울기 개념과 기호를 사용해, 점 $P$ 에서 곡선 $A$ 의 접선의 기울기를 $m_{\tan }$ 라 하면, Barrow 의 정리는 이 기울기가 선분 $X Q$ 의 길이와 같다는 것, 즉 $m_{\tan }=\frac{P X}{T X}=\frac{T X \cdot X Q}{T X}=X Q$ 임을 보여주므로, 현대 의 미적분학 용어와 기호를 도입하면, 그 정리는 " $y=f(x)$ 가 $[a, b]$ 에서 연속 함수이고 $A(x)=\int_{a}^{x} f(t) d t$ (단, $a \leq x \leq b$ ) 을 만족하면 $A^{\prime}(x)=f(x)$ 이다."와 같은 미적분학의 기본정리에 대응한다고 밝힌다.

하지만 이러한 대응은, 마치 Eudoxus 의 비례이론이 Dedekind cut에 정확히 대응한다 고 말하는 것처럼, 현대 미적분학에 대한 지식을 갖고 있는 사람에게 보이는 연결이라는 점에 주의를 기울여야 한다. 엄밀히 말해, Barrow는 함수와 극한 개념을 갖고 있지 않았을 뿐만 아니라 그러한 개념에 기초한 도함수와 정적분 개념도 갖고 있지 않았다. 이런 점에서, Barrow 정리는 변화율 곡선 아래의 넓이가 원래의 변화량 곡선이 된다는 것을 기하학적으 로 설명하거나 입증하는 명제라고 평가하는 것이 타당할 것이다.

한편, 이상의 논의에 비추어보면 Barrow는 적어도 ‘접선문제의 역' 과 ‘넓이문제’ 가 동일 하다는 것을 인지하고 있었다고 할 수 있다[29]. 그러기에, Barrow의 정리는 '곡선과 축에 의해 둘러싸인 넓이를 구하는 문제를 접선문제의 역으로 해결할 수 있다.' 는 암시를 주는 듯하다. 하지만 Barrow 의 옹호자인 Child[12, p. 262]가 "Barrow가 그렇게 일찍 시작한 작업을 (계산술로) 왜 완성하지 않았을까?5)”라고 밝히듯, Barrow는 적어도 '계산' 과 관 련된 사항에 대해서는 별다른 진전을 이루지 못했다. Barrow는 '접선문제의 역' 의 실체가 넓이문제라는 것을 규명했음에도 불구하고, 넓이문제를 '접선 문제의 역' 에 의해 해결할 수 있도록 하는 연산을 제시하지 않았던 것이다. 바로 이 한계가 다음 장에서 밝힐 Newton 과의 간격, 인식론적 장애의 주요한 부분과 깊은 관련이 있다.

5) 이러한 의문에 대해, Child[12, pp. 264-267]는 다음과 같은 추측을 제시하였다: Barrow는 Newton이 해석기하와 Euclid 기하에서 보이는 능력의 부조화에 충격을 받고, 그에게 Euclid 기하에 의해 변화량과 변화율의 관계를 규명해 보이는 교육을 하려 했다. 그러던 중, 1665 년에 발생한 흑사병에 의해 Barrow 와 Newton은 각자의 재능을 살리는 유율법 (fluxional method) 을 개발할 시간을 가지게 되었다. 이후, Barrow는 그의 아이디어가 해석적 방법으로 발전할 것을 알고 있었지만 이 방면에서 자신보다 Newton이 훨씬 나은 능력이 있다는 것을 알았고, 평소에 자신이 원하는 신학공부와 신앙생활을 위해, 자신은 수학계 에서 은퇴하고 Newton이 해석기하학에 의해 유율법을 발전시키게 그 길을 열어주었다. 


\section{Barrow 정리와 관련된 인식론적 장애}

앞선 논의에서, Barrow 가 종합적 방법이 아닌 해석적 방법으로도 $\frac{P X}{T X}=Q X$ 를 입증할 수 있는 능력이 있었다는 가정을 사용한 바 있다. 그런데 이러한 가정은 Barrow의 <기하학 강의록> 10 말미에 부록형태로 등장하는 '계산으로 접선을 구하는 방법' 에 기초한 주장인 데, 이 부분은 Barrow에게서 나타나는 인식론적 장애와 가장 깊은 관련이 있는 곳으로, 그 내용은 다음과 같다[14, p. 113].

$A P, P M$ 을 두 개의 직선일 때, 직선 $P M$ 이 주어진 곡선을 $M$ 에서 자르고, 직선 $M T$ 는 점 $M$ 에서 그 곡선에 접하고 직선 $A P$ 를 $T$ 에서 자른다고 하자. 직선 $P T$ 의 양을 구하기 위해, 곡선의 무한히 작은 호 $M N$ 을 잡자; 그리고서 $M P, A P$ 에 각각 평행한 $N Q, N R$ 을 그린다; $M P=m, P T=t, M R=a$, $N R=e$ 라고 부르겠다. 지금 수행하는 작업에 유용한 직선들에도 이름을 붙이 겠는데, 이 직선들은 주어진 곡선의 특별한 성질을 결정한다; 그리고 계산으로 얻은 방정식을 가지고 $M P, N R$, (그것으로부터 $M P, P T$ 까지) 서로 비교하 겠다; 그러한 과정에서 다음과 같은 규칙을 따른다.

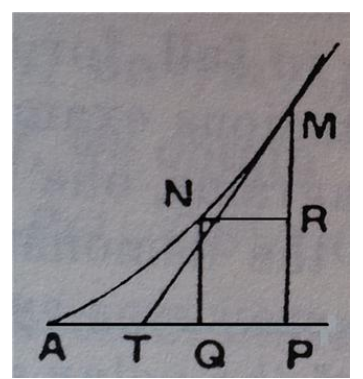

그림 3

규칙1. 계산할 때, $a$ 나 $e$ 의 거듭제곱을 포함한 모든 항들을 생략한다(이 항들은 값이 없다).

규칙2. 방정식을 만든 후에, 기지의 양 또는 결정된 양을 나타내는 문자, $a$ 나 $e$ 로 이루어진 항들을 포함하는 모든 항들을 제거한다(왜냐하면 이 항들을 방정식으로 한 쪽으로 옮기면 반드시 0이 될 것이기 때문이다).

규칙3. $a$ 대신에 $m$ (또는 $M P$ )로, $e$ 대신에 $t$ (또는 $P T$ )로 대체한다. 그러면 $P T$ 의 양을 찾을 수 있다.

여기서, 첫 번째로 드러나는 사항은 Barrow 의 극한개념이 지극히 불완전하다는 것이다. 예를 들어, $a$ 나 $e$ 의 거듭제곱을 포함한 모든 항들을 0 으로 간주하는 규칙 1 과 무한소인 $a$ 와 
$e$ 대신에 각각 $m$ 과 $t$ 로 대체하는 규칙 3 을 논리적으로 정당화하기 위해서는 극한개념이 반 드시 필요한데, 기하적 측면에서 직관적으로 다루려고 할 뿐, 다른 문헌에서 (미분삼각형에 있는) '무한히 작은 호 $M N$ 을 접선의 작은 부분으로 대치해도 된다.' 고 언급한 것 이상으로 극한개념을 발전시키지는 못했다. 이것은 Barrow 가 극한을 산술적으로 생각하지 못했을 뿐만 아니라 그에게 극한개념 자체도 선명하지 않았음을 의미한다[9, p. 184].

하지만 Newton과 Leibniz 역시 불완전한 극한개념을 지니고 있다는 점을 고려하다면, 미적분학의 발달 측면에서 더욱 중요한 사항은 Barrow가 이러한 접선법을 연산 형태로 발전시키지 않았다는 사실이다. 구체적으로 말해, 그는 접선 계산법을 넓이를 구하는 데 적용하지 않았다. 사실, Barrow는 데카르트의 엽선, $x^{n}+y^{n}=a^{n}$ 곡선, $y=a \tan x$ 곡 선에 대한 접선을 작도하는 데 요구되는 접선영 (subtangent) 의 길이를 구하는 5 개의 접선 계산법의 활용 예만을 제시하고 있다[14, 20].

이와 관련해, 그가 접선 계산법을 언급하기에 앞서 남긴 말은 왜 Barrow 가 미적분학 계 산법을 창안하지 못했는가에 대한 이유를 잘 알려준다.

이제는, 앞서 밝혔듯, 우리 주제의 처음 부분을 어떤 형태로 완성했다고 하겠다. 이에 대한 보충으로, 부록의 형태로 우리가 자주 사용하는 계산에 의해 접선을 구하는 방법을 덧붙이고자 한다. 매우 많은 잘 알려지고 익숙한 종류의 방법을 따른 것이지만, 나는 그렇게 하는 것이 어떤 이득이 있는지를 잘 모르겠다. 하 지만 내 친구(후에 Newton으로 알려짐 $)^{6)}$ 의 조언도 있고 해서 그렇게 하겠다: 기꺼이 이렇게 하는 이유는, 내가 논의했던 것들보다 더 유익하고 일반적인 것 처럼 보이기 때문이다[14, pp. 112-113].

Barrow가 그의 수학을 계산술로까지 발전시키기 못한 것은, '어떤 유익이 있는지 잘 모르 겠다.' 는 언급에서 드러나듯, 여러 계산법과 무한소 계산법의 장점을 충분히 인식하지 못했 던 것에 가장 큰 원인이 있다고 하겠다. 사실, 그는 로가리즘과 무한급수 계산을 활용하는 세대에 속하지 않았던 것이다[17]. Barrow 정리와 관련해서도, 만약 그가 무한소 계산법의 힘을 알고 있었다면, 다시금 그 정리를 계산에 의한 접선법으로도 증명했을 것이다. 즉, 앞 절에서의 예측에서와 같이, Barrow 정리 역시 “직선 $T P$ 가 곡선 $A$ 의 점 $P$ 에서의 접선이 되도록 $x$ 축 위의 점 $T$ 를 잡는다면, $T X \times X Q$ 와 $X P$ 가 같게 된다.”와 같은 명제로 바꾸 고, 그 명제를 계산에 의한 접선법으로 매우 간결하게 증명했을 것이다. 하지만 <기하학 강의록> 10 에서 이러한 작업은 이루어지지 않았다.

이러한 분석에 비추어 본다면, Barrow 정리의 특징과 한계가 선명하게 드러나는데, 그 특징과 한계는 한마디로 ‘해석기하학의 불완전한 사용' 이라 할 수 있다. 사실, Barrow는

6) Newton의 편지 중에, Newton의 도움에 의해 Barrow의 <기하학 강의록>에 '계산에 의한 접선법' 이 들어 가게 되었다는 내용이 있다 [25, p. 185] 
곡선 아래의 넓이를 다시 곡선으로 나타내고 있다는 점에서 적어도 '동차성의 원리' 만큼은 극복하고 있다. 넓이를 길이로 간주해서 취급하는 것은 데카르트와 페르마가 도입한 해석 기하학의 핵심 아이디어이다. 하지만 Barrow는 기하학을 대수학으로 바꾸어 계산하는 방 식을 취하지 않고 고전 기하학 체계를 그대로 유지하였다. 한마디로, 해석기하학의 장점을 제대로 살리지 못했던 것이다.

물론, Barrow가 해석기하학과 계산법을 다룰 수 있는 수학적 능력이 있었는지의 여부에 대해서는 여전히 다소간의 논란이 있을 수 있다[18, 30]. 어떤 경우이건, Barrow의 사례는 수학에 대한 신념이 수학적 활동에 영향을 미치는 전형적 경우를 보여주는데, 고전 수학을 지키려고 했던 의지와 신념이 해석기하학과 대수학에 대해 신뢰하지 않는 태도를 낳았고 그것이 수학적 활동으로까지 이어졌다고 볼 수 있다. 예컨대, 해석기하학의 불완전한 사용, 무한소 해석학에 대한 언급과 미적용의 모습은 Barrow 가 고대와 새로운 시대의 수학의 중간에서 투쟁하고 있었음을 보여주는 것이다[24].

Barrow는 변화율 곡선 $Y$ 아래의 넓이를 나타내는 곡선 $A$ 가 곡선 $Y$ 에 대한 변화량 곡 선이 된다는 것을 설명하거나 입증하기 위해, 그 넓이를 직접 구하는 대신에 곡선 $A$ 위의 점 $P$ 에서의 접선의 기울기에 해당하는 $\frac{P X}{T X}$ 가 변화율 곡선 $Y$ 의 높이인 $X Q$ 가 된다는 점을 밝혔다고 볼 수 있다. 특히, 곡선 $Y$ 아래의 넓이를 직접 구하지 않고 곡선 $A$ 가 곡선 $Y$ 에 대 해 변화량 곡선이 된다는 것을 설명한 것은, '접선의 역문제' 와 '넓이문제' 의 관계를 속도거리 사이의 구체적 차원이 아닌 매우 일반적 수준에서 인식하고 있음을 명확히 보여준다. 물론, Barrow 도, Oresme와 Galileo와 마찬가지로, 속도(변화율) 곡선과 거리 (변화량) 곡선의 관계는 속도 곡선 아래의 넓이를 매우 작은 직사각형 또는 직선으로 분할해서, 개별 직사각형의 넓이를 매우 작은 시간동안 이동한 거리라 간주하고 모든 직사각형들의 넓이를 더하게 되면 총 이동거리가 될 것이라고 설명하였다. 그런데 Barrow 의 정리는, 속도 곡선거리 곡선 사이에서뿐만 아니라, 임의의 변화율 곡선에 대해 그 변화율 곡선 아래의 넓이가 어떤 변화량 곡선이 된다는 점을 보여준다는 점에서 매우 일반적인 것이다.

하지만 Barrow는 이처럼 변화율 곡선 아래의 넓이가 변화량 곡선을 형성한다는 것을 넓이를 직접 구하지 않고도 드러냈지만 자신의 방식이 함의하고 있는 가장 큰 장점을 살려 발전시키지는 못했다. 다시 말해, 그는 변화율 곡선과 변화량 곡선 사이의 상호 관계를 이 용해, 어떤 변화율 곡선 아래의 넓이를 접선을 구하는 계산규칙을 가지고 구하는 방법을 제 시하지 못했다. Barrow는 흔히 기하적 미적분학 (geometric calculus) 시대에 속한 인물로 평가하지만, 엄밀하게 보자면 그는 미적분 계산술의 시대에 살지 않았던 것이다.

만약 Barrow 가 변화량 곡선으로부터 계산에 의해 변화량 곡선을 찾는 규칙에 더 주목하 고 그 규칙을 역으로 적용해, 변화율 곡선 아래의 넓이를 구했다면, 물론 그에게 미적분학 의 발명자라는 영예가 주어졌을 것이다. 하지만 그는 자신이 내놓은 수학적 결과의 진정한 
의미를 인식하지 못했다[24]. 변화율 곡선 아래의 넓이가 변화량 곡선이 된다는 관계를 기 하학적으로 밝힌 것은 Barrow 의 공이지만, 그러한 관계를 계산 규칙성 측면에서 대상화 하여 곡선 아래의 넓이를 측정이 아닌 접선법 계산 규칙으로 구한 것은 Newton과 Leibniz 의 몫이었다. 어떤 '관계' 를 안다는 것과 그 '관계의 특성', '관계를 이용해서 얻을 수 있는 유용한 결과' 까지 파악하는 것 사이에는 분명한 수준 차이가 있었던 것이다. 물론, 여기서 접선법의 계산 규칙과 그 이용 가능성에 대한 주목은 그러한 차이를 낳은 한 가지 요인으로 작용했을 수 있다.

\section{4 교수학적 시사점 및 제안}

Klein과 Poincare의 고전적인 역사발생적 교수-학습 원리에 따르면, 역사적 순서를 중시해 미적분 지도에 있어 <적분 $\rightarrow$ 미분 $\rightarrow$ 미적분학의 기본정리, 정적분의 기본정리 ${ }^{7)}>$ 순으로 다루는 교수-학습 계열을 추구하고자 할 것이다. 하지만 이러한 전개 순서를 학교수학에 접목시키기에는 난이도 면에서 상당한 어려움이 따른다. 특히, 미적분을 도입하는 초기에 함수 그래프 아래의 넓이를 구분구적법으로 구하고 정적분을 정의하는 시도 자체가 쉽지 않다. 그래서 국내외 학교수학과 대학수학의 교육과정 및 교과서에서는 대부분 <미분 $\rightarrow$ 적 분 $\rightarrow$ 미적분학의 기본정리, 정적분의 기본정리> 순서를 유지한다. 그런 면에서, 수학사에 대한 분석을 바탕으로 하여 교수학적 시사점과 제안을 하더라도 '미분 $\rightarrow$ 적분' 순서를 유지 한다는 전제 아래 이루어지는 것이 현실적으로 보다 적합할 것이다[1, 3].

한편, 이 연구에서는 Freudenthal이 주창한 현대적인 역사발생적 교수-학습 원리, 즉 수학사를 불연속적 성장의 과정으로 보고 그러한 발달의 역사에서 시사점을 얻어 학습자의 현실에 맞도록 재구성된 역사를 교수-학습에 적용하는 원리를 이론적 배경으로 한다. 따라 서 '미분 $\rightarrow$ 적분' 순서로 구성된 미적분 교수-학습 계열을 유지하면서도 학생들이 수학적 발명의 경험을 할 수 있는데 도움이 되는 교수학적 시사점과 제안을 하는 것이 이 연구의 초점이라 할 수 있다.

이와 관련해, 이 연구에서는 Barrow 정리에 대한 수학사적 분석과 인식론적 장애 차원 에서의 해석을 통해, 다음의 두 가지 교수학적 시사점과 제안을 한다.

첫째, 학생들이 미적분과 관련된 발명의 경험을 하기 위해서는, 그들에게 연속함수 $f(x)$ 아래의 넓이를 나타내는 함수 $\int_{a}^{x} f(t) d t$ 에 대한 도함수를 구해야 할 지적인 필요성을 느끼도 록 하는 교수-학습 상황을 구성해야 한다. 이러한 지적인 필요성을 느끼지 않은 상태에서는, 비록 교사가 정적분에 의해 넓이를 구하는 과정이 역도함수를 구하는 과정에 해당한다는 것을 가르치려 하더라도, 학생들에게 $\frac{d}{d x}\left(\int_{a}^{x} f(t) d t\right)=f(x)$ 와 같은 결과는 한낱 맥락 없이

7) 이 연구에서 '정적분의 기본정리' 는 “ $y=f(x)$ 가 $[a, b]$ 에서 연속이면, 함수 $f(x)$ 의 임의의 원시함수 $F(x)$ 에 대해 $\int_{a}^{b} f(x) d x=F(b)-F(a)$ 이다."를 의미한다. 
도입된 공식 또는 그저 외워야 할 수식에 불과하다고 하겠다.

Barrow 정리는 속도-거리에서 뿐만 아니라 어떤 임의의 변화율 곡선에 대해서도 그 아 래의 넓이를 나타내는 곡선이 그 변화율 곡선에 대한 변화량 곡선이 된다는 것을 보여준다. 물론, Barrow는 속도-거리의 관계를 통해 변화율 곡선으로부터 변화량 곡선을 만들 수 있 다는 추측을 하였고, 이 정리를 통해, 그것에 대해 확인하고 설명하는 작업을 수행했다고 할 수 있다.

그렇다면, 학생들에게 지적인 필요성을 느끼면서 '미적분학의 기본정리' 를 정당화할 수 있도록 지도하는 방식은 무엇일까? Barrow <기하학 강의록>에 나타나듯이 미적분학 발생의 맥락은 변화율과 변화량의 관계였던 반면에 현재 학교수학은 함수, 극한, 도함수, 정적분 개념에 기초했다는 것을 고려한다면, 다음과 같이, 변화율과 변화량의 관계라는 '의 미' 와 함수, 극한, 도함수, 정적분 개념에 기초한 '계산' 을 결합하는 융합적 접근이 가능할 것이다.

우선, 학생들에게 익숙한 거리와 속도의 관계를 다루면서, 거리-시간 함수의 그래프에 대한 접선의 기울기가 속도 그래프를 형성한다는 것을 지도하고, 속도-시간 그래프 아래의 넓이가 이동거리가 된다는 것에 대해 그 넓이를 작은 직사각형으로 분할하고 등속도운동의 경우와 비교하는 활동을 통해 직관적으로 정당화하게 한다. 다음으로, 거리 함수와 속도 함수는 각각 일종의 변화량과 변화율을 나타내는 함수인데, 거리-속도의 경우와 같이, 일반 적으로 변화율 함수 아래의 넓이를 나타내는 함수가 항상 변화량 함수가 될지에 대한 의문을 학생들에게 제기한다.

이때, 변화율 함수 $f(x)$ 와 그에 대한 변화량 함수 $F(x)$ 는 $F^{\prime}(x)=f(x)$ 인 관계를 만족 하므로, 변화율 함수 $f(x)$ 는 $F(x)$ 로부터 미분을 통해 유도되었다는 점에서 $F(x)$ 에 대한 도함수(derivative) 라 부르고, 변화량 함수 $F(x)$ 는 도함수 $f(x)$ 로 미분되기 전의 원래의 양을 나타내는 함수라는 점에서 $f(x)$ 에 대한 원시함수(primitive function) 또는 역도함 수(anti-derivative) 라고 불린다는 점을 밝힌다. 그리고 어떤 변화율 함수에 대한 변화량 함수인 원시함수는 하나가 아니고 여러 개이며 서로 상수값 만큼 차이가 난다는 사실에 대해서는, 평균값의 정리를 이용하지 않고 그림 4 와 같이, 상수항만큼 차이가 나는 함수의 그래프들이 정의구역의 각 점에서 서로 같은 접선의 기울기를 갖게 되는 시각적 자료(기하 탐구형 소프트웨어)를 활용해 직관적 방식으로 지도한다.

이후에는, 정적분의 정의와 그 정의에 따라, 함수 $f(x)$ 아래의 넓이를 나타내는 함수 $S(x)=\int_{a}^{x} f(t) d t$ 를 도입한다. 그리고 변화율 함수가 임의의 연속함수 $f(x)$ 로 주어진 경우 에 대해 그 변화율 함수 아래의 넓이를 나타내는 함수 $\int_{a}^{x} f(t) d t$ 이 함수 $f(x)$ 에 대한 변화 량 함수 원시함수 가 되는지를 알아보는 교수 학습으로 나아간다 물론 $\frac{d}{d x}\left(\int_{a}^{x} f(t) d t\right)=f(x)$ 인지의 여부를 확인해야 하는 상황은, 학생들이 연속함수 $f(x)$ 아래의 넓이함수 $\int_{a}^{x} f(t) d t$ 


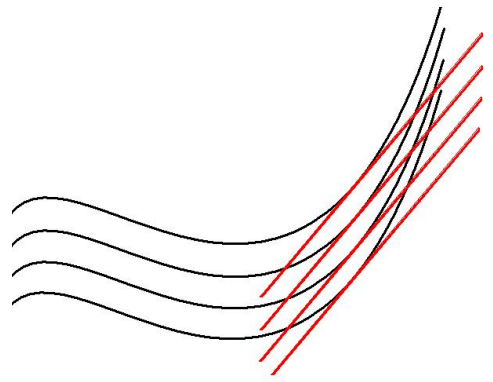

그림 4

에 대한 도함수를 구해야 할 지적인 필요성을 느끼는 장면이어야 할 것이다.

둘째 연속함수 $f(x)$ 에 대해 $\frac{d}{d x}\left(\int_{a}^{x} f(t) d t\right)=f(x)$ 인지의 여부를 의도적으로 알아보는 활동은, Barrow 정리에서와 같이, '넓이문제' 와 '접선문제’ 가 서로 구체적으로 연결되는 방식으로 수행될 필요가 있다8) . 현재 학교수학에서 '미적분학의 기본정리' 에 대한 증명은 폐구간에서 연속함수가 최댓값과 최솟값을 가진다는 성질에 기초해 도함수 개념에 의해 증명하는 방식을 취하지만, 시각적으로 넓이문제와 접선문제의 관련성을 보여주지 못하 는 단점이 있다. Barrow가 유클리드 기하에 머물러 미적분학 계산술의 단계로 넘어가지 못했던 반면, 오늘날의 학생들은 계산에 치중된 학습을 하게 되어 기하적 직관과 계산을 연결시키지 못하고 있다고 할 수 있는 것이다.

Barrow 가 겪었던 인식론적 장애와 학생들이 겪는 어려움 사이에는 그 성격과 원인에 있어 차이가 있겠지만, 기하적 직관과 계산을 연결시키지 못한다는 점에서 공통점이 있다. 학교수학의 접근방식을 개선시키기 위해서는, Barrow 의 기하적 접근방식과 학교수학의 도함수에 기초한 접근방식을 결합시킬 필요가 있는데, 이에 대한 방안 중 하나는 "넓이문 제' 와 '접선문제' 의 관련성을 보여주면서 도함수 개념을 토대로 해 미적분학의 기본정리를 증명하는 것이라 하겠다.

첫 번째 제안이 변화율과 변화량의 관계라는 ‘의미' 와 함수, 극한, 도함수, 정적분 개념에 기초한 '계산' 의 결합을 시도하면서 지적 필요성을 자극하는 목적 지향적 교수-학습 계열을 제시하는 것이라면, 두 번째 제안은 접선의 기울기와 함수 그래프 아래의 넓이와 관련된 '기 하적 직관' 과 함수, 극한, 도함수, 정적분 개념에 기초한 '계산' 의 결합을 시도하는 교수학습 방안을 제안하는 것이라 할 수 있다. 한편, 이러한 두 번째 제안은 현재의 학교수학의 모습에 큰 변화를 주지 않고도, 탐구형 기하소프트웨어를 이용해, 그림 5 에서와 같이, 함수 $f(x)$ 의 그래프와 함수 $S(x)=\int_{a}^{x} f(t) d t$ 의 그래프를 동시에 다루는 활동에 의해 구현할 수 있다.

8) 이러한 제안은, 미분은 ‘접선을 구하는 활동’ 이고 적분은 ‘넓이를 구하는 활동’ 이라는 기하적 의미 를 강조하 자는 것이 아니라, 미적분학의 기본정리를 다룸에 있어 '넓이문제' 와 '접선문제' 의 관련성을 직접 보여주자는 것이다. 
Barrow 정리는 변화율 곡선 $Y$ 의 넓이 값에 의해 생성한 곡선 $A$ 에 대해 그 곡선 $A$ 위의 점 $P$ 에서의 접선의 기울기에 해당하는 $\frac{P X}{T X}$ 가 변화율 곡선 $Y$ 의 높이인 $X Q$ 가 된다는 점을 직관적으로 드러내는 장점이 있는데, 이러한 Barrow 정리의 가장 큰 장점과 계산 위주의 학교수학을 결합하는 방식은, 연속함수 $f(x)$ 에 대해 $\frac{d}{d x}\left(\int_{a}^{x} f(t) d t\right)=f(x)$ 을 증명함에 있어, 함수 $\int_{a}^{x} f(t) d t$ 의 그래프에 대한 접선의 기울기 값이 함수 $f(x)$ 값이 된다는 것을 시 각적으로 보여주는 것이다.

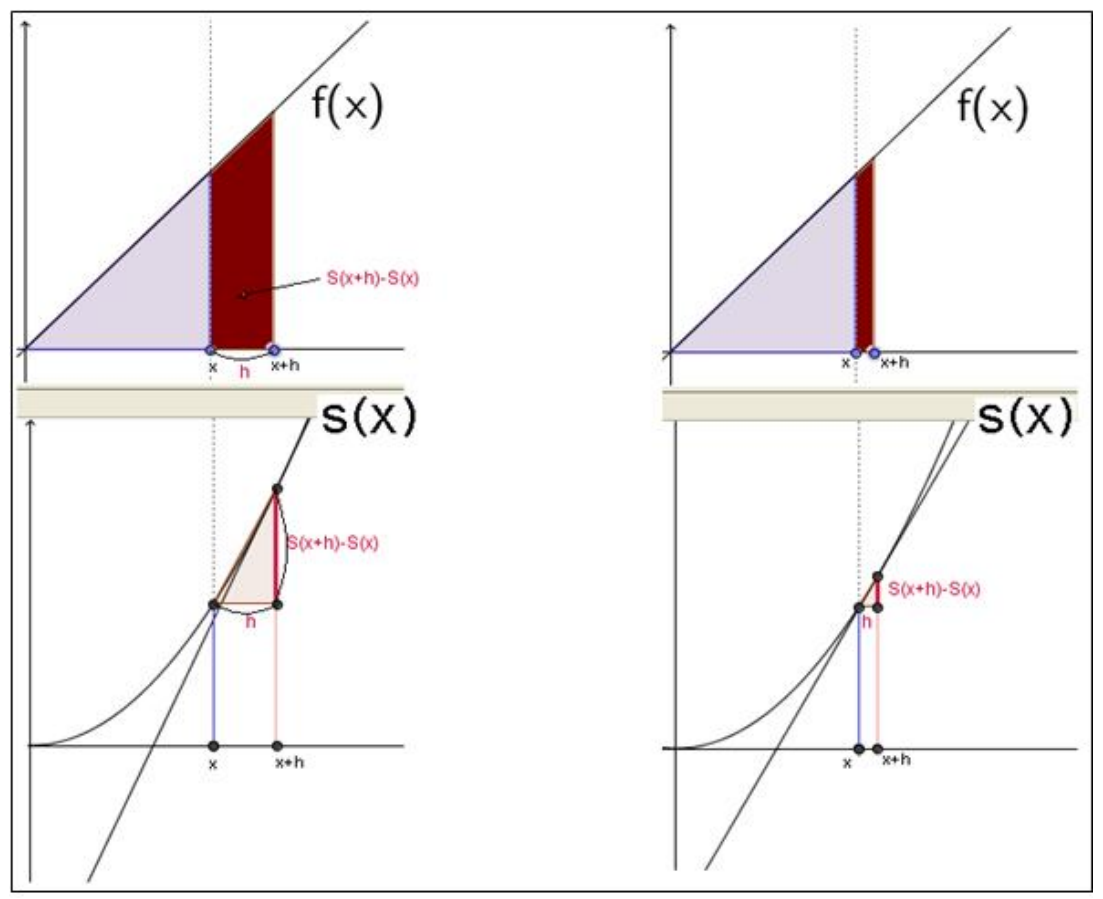

그림 5

구체적으로, $S(x)=\int_{a}^{x} f(t) d t$ 일 때, $h \rightarrow 0$ 에 따라, 그래프에서 $S(x+h)-S(x)$ 넓이 값에 해당하는 도형이 점점 사다리꼴 사각형 모양에 가까워지면서 $\frac{S(x+h)-S(x)}{h}$ 의 값 이 $f(x)$ 값에 수렴하게 되는 첫 번째 과정과 $S(x)$ 그래프에서 할선이 접선으로 변해가면서 $\frac{S(x+h)-S(x)}{h}$ 값이 접선의 기울기 값에 수렴하게 되는 두 번째 과정을 동시에 서로 연 동해서 보여주면서 관찰하게 하는 것이다. 이 때, 어떤 함수 그래프 아래의 넓이를 새로운 함수의 그래프로 나타내고 $\frac{S(x+h)-S(x)}{h}$ 의 값의 변화를 보여주는 탐구형 기하소프트 웨어를 사용하는 것이 효과적일 수 있다.

\section{5 결론}

Barrow 정리에 대한 수학사적 분석을 통해, Barrow 가 '접선문제의 역' 과 '넓이문제' 가 동일하다는 것을 매우 일반적인 수준에서 인지하고 있었음을 알 수 있었다. 하지만 Barrow 
는 '접선문제의 역' 의 실체가 넓이문제라는 것을 규명했음에도 불구하고, 넓이문제를 '접선 문제의 역' 에 의해 해결할 수 있도록 하는 연산을 제시하지 않았다. 그런데 이러한 사항은

Barrow 정리의 '해석기하학의 불완전한 사용' 이라는 특징과 한계를 단적으로 보여준다고 할 수 있다. 다시 말해, Barrow는 곡선 아래의 넓이를 다시 곡선으로 나타내고 있다는 점 에서 적어도 ‘동차성의 원리' 만큼은 극복하였지만, 기하학을 대수학으로 바꾸어 계산하는 방식을 취하지 않고 고전 기하학 체계를 그대로 유지하였다.

이 연구에서는, 이러한 수학사적 분석 결과를 바탕으로 현재의 우리나라 고등학교 미적분 학 교수-학습에 접목시킬 수 있는 다음의 두 가지 제안을 하였다. 첫째, 연속함수 $f(x)$ 아래 의 넓이를 나타내는 함수 $\int_{a}^{x} f(t) d t$ 에 대한 도함수를 구해야 할 지적인 필요성을 느끼도록 하는 교수-학습 상황을 구성할 것을 제안하였다. 둘째, 미적분학의 기본정리는, Barrow 정 리에서와 같이, '넓이문제’ 와 '접선문제’ 가 서로 구체적으로 연결되는 방식으로 다룰 것을 제안하였다.

한편, 미적분 지도와 관련해, <미분 $\rightarrow$ 적분>의 교수-학습 계열을 유지한다면 <역도함 수 $\rightarrow$ 정적분 $\rightarrow$ 넓이함수 $\int_{a}^{x} f(t) d t$ 의 도입 $\rightarrow$ 미적분학의 기본정리, 정적분의 기본정리 $\rightarrow$ 역도함수로서의 부정적분 도입>의 순서로 지도하는 것이 바람직하다는 주장이 국내외 에서 제기된 바 있다 $([2,4,5,16,28])$. 그러한 주장은 미분과 적분의 관계에 대한 이해를 위해 수학 내용 전개의 논리적 측면에서 볼 때 '부정적분' 용어와 기호의 도입 시기에 대해 조정해야 함을 제안한 것이라 할 수 있다.

이와 비교할 때, 이 연구에서 제시한 두 가지 교육적 제안은 '미분의 역' 과 '적분' 이 동 일하다는 것을 인식시키기 위해 각각 '의미' 와 '계산' 의 결합, '기학적 직관' 과 '계산' 의 결합을 이루게 하는 목표 지향적이고 의미 지향적인 활동에 해당한다고 하겠다.

물론, 이 연구에서 제안한 사항도 결국에는 '계산' 으로 귀결될 수밖에 없다. 즉, 어떤 연속 함수 $f$ 에 대한 역도함수 $F$ 가 주어진 경우, $\int_{a}^{b} f(t) d t$ 를 구하기 위해 정적분을 이용해 넓이 를 직접 찾는 대신에 $\int_{a}^{b} f(t) d t=F(b)-F(a)$ 와 같은 공식을 활용하게 하는 교수-학습에 이를 것이다. 이런 점에서, 이 연구는 학생들이 미분과 적분의 관계를 충분히 이해하면서 미적분 계산을 하도록 도와주고자 하는 교육적 제안이라 할 수 있을 것이다.

\section{참고 문헌}

1. 김남희 외, 『수학교육과정과 교재연구』, 경문사, 2011.

2. 고종숙, 『수학 바로 보기』, 여울, 2004.

3. 민세영, 『역사발생적 수학 학습-지도 원리에 관한 연구』, 서울대학교 박사학위 논문, 2002.

4. 정연준, 『미적분의 기본정리에 대한 교수학적 분석』, 서울대학교 박사학위 논문, 2010.

5. 정연준, 이경화, 「부정적분과 정적분의 관계에 관한 고찰」, 학교수학 $11(2009)$, No. 2, pp. 301-316. 
6. 한경혜, 『수학사 도입의 이론적 근거 - 역사 발생 원리와 해석적 방법론』, Proceeding of HPM2012 Book 1 (2012), pp. 59-72.

7. Baron, M. E., The Origins of the Infinitesimal Calculus, Dover Publications, Inc., New York, 1969.

8. Bell, J. L., The Continuous and the Infinitesimal in Mathematics and Philosophy, Polimetrica, International Scientific Publisher, Monza-Milano (Italy), 2006.

9. Boyer, C. B., The History of the Calculus and Its Conceptual Development, Dover Publications, Inc., New York, 1949.

10. Boyer, C. B., 김경화 역, 『미적분학사: 그 개념의 발달』, 교우사, 2004. (원저는 1949년 출판).

11. Brousseau, G., Theory of Didactical Situations in Mathematics Education, Kluwer Academic Publishers, 1997.

12. Child, J. M., "The Lectiones Geometricae of Isaac Barrow", Monist 26(1916), No. 2, pp. 251-267.

13. Child, J. M., The Geometrical Lectures of Isaac Barrow, Open Court Publishing Co., 1916.

14. Child, J. M., The Geometrical Lectures of Isaac Barrow (Lecture X), The Treasury of Mathematics (H. O. Midonick Ed.), Philosophical Library, New York, 1965, pp. 106-115.

15. Coolidge, J. L., "The Story of Tangents", The American Mathematical Monthly 58(1951), Issue 7, pp. 449-462.

16. Courant, R., Differential and Integral Calculus, Vol. 1, Interscience Publishers-John Wiley \& Sons, Inc., 1988.

17. Edwards, C. H., The Historical Development of the Calculus, Springer-Verlag, New York, 1979.

18. Feingold, M., "Newton, Leibniz and Barrow Too: An Attempt at a Reinterpretation", Isis 84(1993), No. 2, pp. 310-338.

19. Flashman, M. E., "Historical Motivation for a Calculus Course: Barrow's Theorem", Vita Mathematica (R. Calinger Ed.) MAA Notes 40(1996), pp. 309-315.

20. González-Velasco, E. A., Journey Through Mathematics, Springer, New York, 2012.

21. Jahnke, H. N., The use of original sources in the classroom: empirical research findings, History in Mathematics Education (J. Fauvel, \& J. V. Maanen Eds.), Kluwer Academic Publishers, Dordrecht, 2000, pp. 291-328.

22. Jankvist, U. T., "A categorization of the whys and hows of using history in mathematics education," Educational Studies in Mathematics 71(2009), No. 3, pp. 235-261.

23. Kline, M., Mathematical Thought from Ancient to Modern Times, Oxford University Press, New York, 1972.

24. Mahoney, M. S., Barrow's mathematics: between ancients and moderns, Before Newton: The Life and times of Isaac Barrow (M. Feingold Ed.), Cambridge University Press, New York, 1990, pp. 179-249.

25. More, L. T., Isaac Newton: A biography, Dover Publications, New York, 1962.

26. Radford, L., "Historical formation and student understanding of mathematics," History in Mathematics Education (J. Fauvel, \& J. V. Maanen Eds.), Kluwer Academic Publishers, Dordrecht, 2000, pp. 143-170.

27. Sierpinska, A., Understanding in Mathematics, The Palmer Press, Washing, DC, 1994. 
28. Stewart, J., Calculus-Early Transcendentals, Belmont, Brooks \& Cole., CA, 2008.

29. Struik, D. J., A Source Book in Mathematics: 1200-1800, Harvard University Press, 1969.

30. Whiteside, D. T., "Isaac Newton: Birth of a Mathematician," Notes and Records of the Royal Society of London 19(1964), pp. 53-62.

PARK SunYong

Department of Mathematics Education, Yeungnam University

E-mail: polya@yu.ac.kr 
학자들은 수학계를 대변할 능력을 잃었다. 이에 국제적인 의무감을 갖게 된 미국의 스톤(Stone)을 비롯한 수학자들은 정치에 상관없이 모든 나라가 가입할 수 있는 새 IMU를 탄생시킨다. 이 논문은 제2 차 세계대전 이후에 IMU의 재탄생 과정과 1950년도의 ICM에서 일어난 일들을 면밀히 알아봄으로써 20세기 중반의 수학계의 발전상을 연구하고자 한다.

Sun Bo Euk 서보억, A Historical Process Analysis and Extension of Division into Equal Parts in Middle School Geometry 『중학교 기하영역 등분할 개념에 대한 수학사적 분석 및 확장에 대한 연굴

본 연구에서는 중학교 기하영역에서 다루어지는 등분할 개념을 조사하고, 이를 바탕으로 수학사적 분석을 통해 등분할 개념에 대한 확장 가능성을 탐구한 문헌연구이다. 중학교 기하영역에 대한 조사를 통해 선분의 등분할, 각의 등분할, 호의 등분할, 넓이의 등분할 개념이 다루어지고 있음을 발견하였다. 이들 네 개의 등분할 개념에 대한 수학사적 분석을 통해 역사적으로 등분할 개념이 다양한 측면에서 다루어졌음을 확인할 수 있었다. 최종적으로 선분의 등분할 개념과 각(호)의 등분할 개념은 방법적 측면에서의 확장에 대해 고찰하였고, 넓이의 등분할 개념은 개념적 측면에서의 확장에 대해 탐색하였 다. 본 연구에서 제시한 등분할에 대한 수학사적 분석 및 확장에 대한 분석 결과를 통해 중등학교에서 수학사의 효과적 활용에 대한 방향 설정이 기대된다.

JANG Yun Sun, KIm Sung Joon 장윤선, 김성준 A Study on the Usage of Mathematics Notes in Elementary School Classes 『수학노트 활용 사례에 대한 조사 연구』

본 연구는 학교수학과 수학적 의사소통을 연계하기 위한 방안으로 초등학교 현장교사들이 수업에서 사용하고 있는 수학노트의 활용 사례를 살펴본다. 수학적 의사소통은 말하기, 듣기, 읽기 활동까지를 포괄하지만 여기서는 수학적 쓰기 활동, 특히 수학노트의 활용과 관련된 목적과 필요성, 유형 등에 대해 알아본다. 이를 위해 교사들과의 면담과 서술형 설문지를 통해 수학노트의 사용 이유, 수학노트에 담을 내용, 수학노트 사용에 따른 변화 등에 대한 교사들의 전반적 인식을 살펴본다. 본 연구는 교사들에게 수학적 사고력 또는 계산 능력의 신장을 포함한 수학노트의 활용 효과와 그에 대한 정보 제공 및 수학 노트 사용을 위한 기초자료의 제시를 목적으로 한다.

PARK SunYong 박선용, A Historical Analysis of Barrow's Theorem and Its Educational Implication ${ }^{\circledR}$ Barrow 정리의 수학사적 분석과 그에 따른 교육적 시사점에 대한 연 구』

이 연구에서는 수학사에 대한 해석학적 관점에서 Barrow 정리의 특징에 대해 분석하고, 현대적인 역사발생적 원리에 기초해 수학적 재발명 활동을 이끄는 미적분학 교수-학습 계열에 대해 논의한다. Barrow 정리에 대한 수학사적 분석을 통해서는, 그 정리의 기하학적 특성을 드러내고, 그 정리를 다룬 Barrow 의 의도에 대해 추측하고, Barrow 가 겪은 인식론적 장애에 대해 고찰하였다. 그리고 이러한 분석을 바탕으로 하여, 학생들이 '적분’ 과 ‘미분의 역' 이 같다는 것을 인식하도록 하기 위한 목적 지 향적이고 의미 지향적 교수-학습을 제안하고 현재 학교수학 미적분학에서 보완해야 할 사항에 대해 지적하였다.

KIm Chang Il, LeE Bong Ju 김창일, 이봉주 Mathematics Classroom in Departmentalized Classroom System: What are Required for Effective Establishment 『수학과 교과 교실의 효율적인 환경 구성과 운영을 위한 방향 탐색』 